\title{
(2) OPEN ACCESS \\ Return to play after surgery for isolated unstable syndesmotic ankle injuries (West Point grade IIB and III) in 110 male professional football players: a retrospective cohort study
}

\author{
Pieter D'Hooghe $\odot,{ }^{1}$ Alberto Grassi $\odot,{ }^{2}$ Khalid Alkhelaifi, ${ }^{1}$ James Calder, ${ }^{3}$ \\ Thomas PA Baltes, ${ }^{4,5,6}$ Stefano Zaffagnini, ${ }^{2}$ Jan Ekstrand ${ }^{1}$
}

'Orthopedic Surgery, Aspetar Qatar Orthopaedic and Sports Medicine Hospital, Doha, Qatar ${ }^{2}$ lla Clinica Ortopedica e Traumatologica, IRCCS Istituto Ortopedico Rizzoli, Bologna, Italy

${ }^{3}$ Trauma \& Orthopaedics,

Chelsea \& Westminster Hospital, London, UK

${ }^{4}$ Research Department, Aspetar Orthopaedic and Sports Medicine Hospital, Doha, Qatar ${ }^{5}$ Department of Orthopaedic Surgery, Academic Medical Center, Amsterdam, The Netherlands

${ }^{6}$ Academic Center for Evidence Based Sports Medicine (ACES) Amsterdam, The Netherlands

\section{Correspondence to}

Dr Pieter D'Hooghe, Orthopedic Surgery, Aspetar Qatar Orthopaedic and Sports Medicine Hospital, Doha 29222, Qatar;

pieter.orthopedie@gmail.com

Accepted 14 August 2019 Published Online First 31 August 2019

\section{ABSTRACT}

Objectives To evaluate time to return to play following surgical stabilisation of isolated unstable syndesmosis injuries in a cohort of professional male football players. Methods All professional football players undergoing surgery for isolated unstable syndesmosis injury (West Point grade $\geq|| B$ ) at a specialised Orthopaedic and Sports Medicine Hospital were followed up until return to play (minimum $\geq 6$ months). Players with a stable syndesmosis, injuries older than 6 weeks, concomitant medial or lateral malleolar fracture or previous ankle surgery were excluded. During rehabilitation, time required to return to sports-specific rehabilitation, team training and first match play, were recorded.

Results Between January 2012 and December 2017, a total of 110 male professional football players were included. The mean time required to begin on field rehabilitation was $37 \pm 12$ days, while the mean time to return to team training was $72 \pm 28$ days. The first official match was played on average $103 \pm 28$ days postoperatively. Multivariable analysis revealed that the severity of injury, the concomitant presence of talar cartilage injury and the age of the player were significantly associated $(p<0.00001)$ with time to return to on field rehabilitation, team training and match play. Conclusion In this cohort of professional football players, surgical stabilisation of isolated unstable syndesmosis injuries (West Point grade $\geq \| \mathrm{B}$ ) allowed for relatively quick return to play. High grade injury (West Point grade III), concomitant cartilage injury and greater age were associated with longer return to play times. Level of evidence Longitudinal observational cohort study (level II).

\section{INTRODUCTION}

Although the incidence of isolated syndesmosis injury among professional football players is low, existing data suggest it causes a mean time loss of 39 days and an injury burden of 1.8 days absence per/ 1000 hours of exposure. ${ }^{12}$ Current treatment algorithms subdivide syndesmotic injury based on MRI findings (tear of the antero-inferior tibiofibular ligament (AITFL), interosseous ligament (IOL) and postero-inferior tibiofibular ligament (PITFL)) (figure 1) and physical examination (squeeze test and external rotation stress test). ${ }^{3-8}$

Based on MRI findings syndesmosis injury can be classified as West Point grade I (sprain of AITFL) and West Point grade III (complete disruption of all syndesmotic ligaments with frank diastasis)..$^{5}$ MRI findings for West Point grade IIA (stable) and IIB (unstable) include complete tear of the AITFL and injury of the IOL and are differentiated based on a positive squeeze test. Despite there having been no randomised controlled trials as to how to manage these subcategories of syndesmosis injuries, most clinicians advocate conservative measures for stable low-grade syndesmosis injuries (West Point $\leq$ IIA), and surgical stabilisation of high-grade unstable (West Point $\geq$ IIB) syndesmosis injuries. ${ }^{39}$

Surgical fixation of unstable syndesmotic injuries is performed in elite athletes as it is claimed to shorten return to play times. ${ }^{10}{ }^{11}$ However, there has only been one study that investigated return to play after surgical treatment of unstable syndesmosis injuries. In 2016, Calder et al reported the results of 36 athletes who underwent surgical stabilisation of a West Point grade IIB unstable syndesmotic injury. Athletes were able to return to play after a mean 65 days (range, 27-104 days). ${ }^{12}$ However, as this study included athletes from a variety of sports, demand for a study investigating return to play times in professional football players remains.

Therefore, the aim of this study was to determine the time required to return to on field rehabilitation, team training and official match play, following surgical stabilisation of isolated unstable syndesmosis injuries ( $>$ grade IIB) in a cohort of professional male football players.

\section{METHODS}

Patient selection

In this retrospective cohort study, we evaluated the time required to return to sport-specific rehabilitation, team training and to first match play, in a consecutive series of professional football players that underwent surgical fixation of an isolated, unstable ankle joint syndesmosis injury at our institution between January 2012 and December 2017.

Patients were eligible for this study if they were registered professional football players with the QFA (Qatar Football Association, compromising around 480 players per season), had sustained a syndesmotic ankle injury, graded as West Point (Clinical) IIB or III, and had completed a minimal postoperative follow-up of 6 months. The preoperative classification of syndesmotic injury was based on clinical examination (squeeze test and external rotation test) and a detailed MRI report by a radiologist at our 

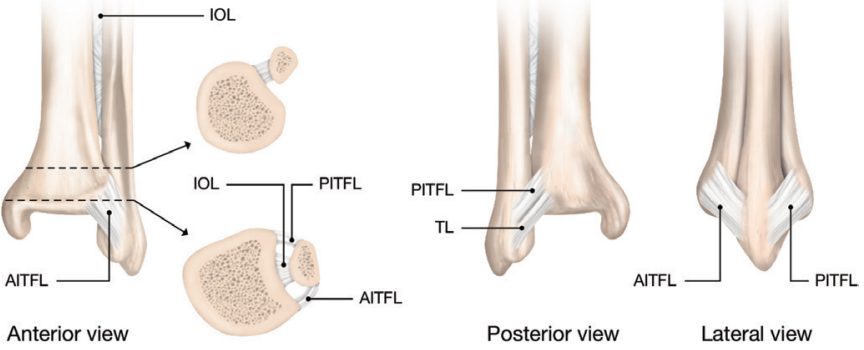

Figure 1 Graphic anatomical image of the three syndesmotic ankle ligaments. AITFL, anterior inferior tibiofibular ligament; IOL, interosseous ligament; PITFL, posterior inferior tibiofibular ligament.

centre that was blinded to the patient's details. Only lesions graded by MRI to be isolated IIB and III were included in the study and indicated for surgical fixation (figure 2).

Football players with injuries older than 6 weeks, any previous ankle surgery or with a concomitant lateral or medial malleolar ankle fracture were excluded.

After surgery, the time to return to sport-specific rehabilitation was documented and retrieved from the player's physiotherapist while the time to return to team training and official first match was documented and retrieved from the player's football club team doctor.

The criteria to return to sport-specific rehabilitation that we used were: normal gait, stability in single-leg balance stance, able to perform pain-free a single-leg calf raise, a deep 'catcher squat', a single-leg hop and jog limp-free without any shortened stride or step length.

\section{Patient involvement}

All football players who participated in the study signed a preoperative surgical informed consent mentioning they agreed to participate in the study. The players were all involved in the conduct of the study since they were all contacted to report their exact dates of return to play. The research question did not change during the study progress and all players were informed on the results of their personal study data.

\section{Surgical technique}

A fellowship-trained Sports Medicine Surgeon (PD'H) performed all surgical procedures. General anaesthesia was used in all procedures. Patients were positioned in the supine position. Standard 2-portal anterior ankle arthroscopy (anteromedial and

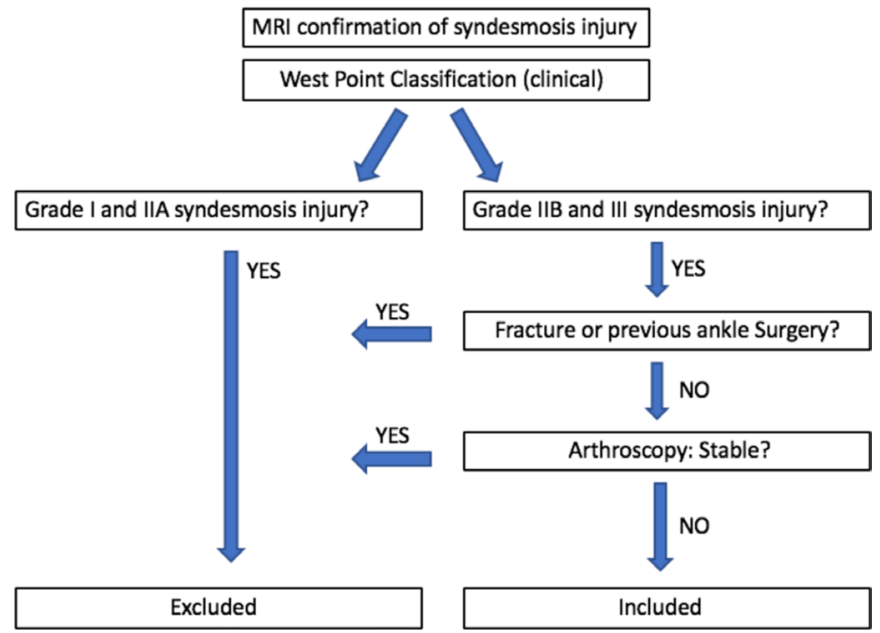

Figure 2 Selection algorithm to decide on inclusion in the study. anterolateral) was performed to confirm syndesmotic instability. The distal syndesmosis was considered unstable if a $5.0 \mathrm{~mm}$ shaver blade could be gently introduced into the distal syndesmosis, $1 \mathrm{~cm}$ above the talocrural joint.

Lateral incision over the distal fibula $2-3 \mathrm{~cm}$ proximal to the tibiotalar joint was performed after confirmation of an isolated unstable syndesmosis. In order to achieve correct fibular reduction into the tibial incisural notch, a reduction Weber clamp was used under fluoroscopic control in anteroposterior and lateral views. A Kirschner wire (K-wire) was inserted from the distal fibula (incision) to the distal tibia under fluoroscopy in anteroposterior and lateral views with the ankle in neutral position. The K-wire was overdrilled by a 4-mm cannulated drill and the suture button (Tightrope, Arthrex) was inserted. The suture button was passed through the medial tibial cortex under fluoroscopic control and the tibiofibular joint reduction was completed after tightening the pulley. After confirmation under fluoroscopy that the suture button is located flush on the bone, the construct was hand tied on the lateral side with the ankle in neutral position. A second suture button was placed $1 \mathrm{~cm}$ proximal to the other one in case of a combined posterior malleolar fracture or deltoid ligament rupture.

Postoperatively, all players were allowed to mobilise immediately and partial weightbearing in a pneumatic cam boot was initiated for the first 10 days postoperatively. Range of motion was not restricted from day 1 postoperatively. After 10 days of partial weightbearing, the boot was removed and full mobilisation of the ankle was then allowed. Strengthening and running were allowed after 3 weeks. Full return to competitive sports was permitted according the individual progression.

\section{Statistical analysis}

Statistical analysis was performed with the software MedCalc. Continuous variables were expressed as mean and SD, while categorical variables were expressed as the percentage of the entire group. The comparison between different subgroups was performed with the independent sample t-test for continuous variable, and with the Fisher exact test for categorical variables.

A Kaplan-Meier curve was calculated using three different endpoints: the time to on field rehabilitation, the time to return to train with team and the time to return to first match. For each of these outcomes, the rate and SE of the player that reached the endpoint at weekly time-points were calculated for the whole series and for the subgroups based on injury severity. The Log-rank test was used to compare the curves of the two subgroups based on injury severity.

A multivariate analysis was performed in a stepwise fashion using as outcomes: the time to on field rehabilitation, the time to return to train with team and the time to return to first match. This multivariate analysis used as independent variables: the patients' characteristics, age, injury severity, presence of concomitant talar cartilage injury, reinjury, dominant leg, match injury and contact injury. The multivariate analysis was corrected in order to have 25 years as the reference age of the players to calculate the constant coefficients. Values were considered as statistically significant with a $p<0.05$.

\section{RESULTS}

Between January 2012 and December 2017, a total of 123 professional football players were assessed for eligibility in this study. Thirteen players were excluded; six players with a concomitant fracture of the medial or lateral malleolus; five for having undergone previous ankle surgery and two patients were excluded as they were diagnosed with a stable syndesmosis lesion (West Point IIA) at the time of arthroscopy. No players were lost to follow-up thanks to the 


\begin{tabular}{lcllc}
\hline Table 1 & Patientand injury characteristics & \\
\hline & Total & $\begin{array}{l}\text { Grade IIB } \\
(\mathbf{n}=75)\end{array}$ & $\begin{array}{l}\text { Grade III } \\
(\mathbf{n}=35)\end{array}$ & P value \\
\hline Age & $24.9 \pm 4.0$ & $25.4 \pm 4.1$ & $23.8 \pm 3.3$ & 0.0586 \\
\hline Dominant leg & & & & 1 \\
\hline No & $45(40 \%)$ & $31(41 \%)$ & $14(40 \%)$ & \\
\hline Yes & $65(60 \%)$ & $44(59 \%)$ & $21(60 \%)$ & \\
Grade & & & & \\
\hline IIB & $75(68 \%)$ & $75(100 \%)$ & $0(0 \%)$ & NA \\
\hline III & $35(32 \%)$ & $0(0 \%)$ & $35(100 \%)$ & \\
Cartilage injury & & & & $=1.0000$ \\
\hline No & $87(79 \%)$ & $66(88 \%)$ & $21(60 \%)$ & \\
\hline Yes & $23(21 \%)$ & $9(12 \%)$ & $14(40 \%)$ & \\
\hline Reinjury & & & & \\
\hline No & $102(93 \%)$ & $69(92 \%)$ & $33(94 \%)$ & \\
\hline Yes & $8(7 \%)$ & $6(8 \%)$ & $2(6 \%)$ & \\
\hline Event & & & & \\
\hline Training & $34(31 \%)$ & $25(33 \%)$ & $9(26 \%)$ & $=0.5091$ \\
\hline Match & $76(69 \%)$ & $50(67 \%)$ & $26(74 \%)$ & \\
\hline Mechanism & & & & \\
\hline Contact & $40(36 \%)$ & $15(20 \%)$ & $25(71 \%)$ & \\
\hline Non-contact & $70(64 \%)$ & $60(80 \%)$ & $10(29 \%)$ & \\
\hline Situation & & & & \\
\hline Tackled & $40(36 \%)$ & $15(20 \%)$ & $25(71 \%)$ & \\
\hline Twist & $40(36 \%)$ & $33(44 \%)$ & $7(20 \%)$ & \\
\hline Landing from jump & $17(16 \%)$ & $14(19 \%)$ & $3(9 \%)$ & \\
\hline Unknown & $13(12 \%)$ & $13(17 \%)$ & $0(0 \%)$ & \\
\hline & & & & \\
\hline & & & \\
\hline
\end{tabular}

direct contact with the player's physiotherapists and football club team doctors.

\section{Population and injury characteristics}

A total of 110 male football players with a mean age at surgery of $24.9 \pm 4.0$ years old were included in this study. All of them $(100 \%)$ were available for follow-up and their mean follow-up duration was $11.3 \pm 3.0$ months. The syndesmotic injury involved predominantly the dominant leg $(60 \%)$ and most commonly resulted from a non-contact mechanism (64\%) such as twist (36\%) or landing from a jump (16\%). The majority of the injuries occurred during match play (69\%). Only $7 \%$ of them were classified as reinjury. According to arthroscopic evaluation, 75 (68\%) were graded as a grade IIB and $35(32 \%)$ were as a grade III injury. Concomitant talar cartilage injury was observed in 23 patients (table 1).

\section{Return to sport outcomes}

The mean time required to begin the sports-specific rehabilitation was $37 \pm 12$ days, while the time to return to train with team was $72 \pm 28$ days. The first official match after surgical syndesmosis fixation was played on average after $103 \pm 28$ days (table 2).

Mean time-loss for unstable grade IIB injuries are shown in table 2 and those for grade three injuries are presented in table 3.

One month postoperatively, $55 \%$ of players had started on field rehabilitation, $4 \%$ had already returned to team training and none had participated in an official match. At 2 months, almost all of the players (97\%) had started sport-specific rehabilitation, $47 \%$ were training with their team and $4 \%$ had already participated in an official match. At 3 months $73 \%$ of the players were allowed to train with their team and nearly half (44\%) had played an official match. The return to training and to match play were respectively $95 \%$ and $76 \%$ at 5 months and $98 \%$ and $95 \%$ at 6 months (figure 3).
During the postoperative follow-up, 5 patients (5\%) experienced delayed wound closure. None of these patients required additional treatment and all healed within 50 days after surgery.

\section{Analysis based on injury severity}

Patients who were diagnosed as having a grade III injury presented with a higher rate of concurrent talar cartilage injury (40\%) $(p=0.0019)$, an almost fourfold higher rate than patients with a grade IIB injury (12\%). Moreover, in patients with grade III injury, the mechanism of injury was predominantly due to contact with another player during a tackle $(71 \%)(p=0.0001)$; more than a threefold greater compared with patients with grade IIB injuries (20\%). Patient's age, reinjury type and match or training injury were not different between these two subgroups.

Considering sport-related outcomes, a longer time to sportspecific rehabilitation $(\mathrm{p}<0.0001)$, return to team training $(p<0.0001)$ and return to match play $(p<0.0001)$ were observed in those patients diagnosed with a grade III injury (table 3 ).

In particular, all players with grade IIB injuries had started sportspecific rehabilitation after 8 weeks, compared with $80 \%$ with grade III injuries. Similarly, all players classified as having sustained a grade IIB injury, had returned to team training after 3 months, compared with only $14 \%$ of the athletes with a grade III injury.

Finally, all athletes with a grade IIB injury had played an official match within 4 months compared with only $26 \%$ of those with a grade III injury (figure 4).

According to the multivariable analysis, the injury severity, the presence of talar cartilage injury and the age at surgery were significant predictors $(\mathrm{p}<0.0001)$ in all the three models of return to sportspecific rehabilitation, return to team training and return to match play (table 4).

The average time expected to begin sport-specific rehabilitation for a 25 years old player, with a grade IIB injury and no talar cartilage involvement was 31.2 days. This is lengthened by an average of 16 days in the presence of a grade III injury, 4 days in the case of talar cartilage injury, and 0.4 days every year younger than 25 , or shortened by 0.4 days every year older than 25 . Similarly, the expected time to return to team training for the same profile of player ( 25 years old, type IIB injury, no cartilage injury) was 56.4 days, which is delayed by a mean 43 days in the case of a grade III injury, 10 days in the case of a talar cartilage injury and 0.8 days every year younger than 25 , while shortened 0.8 days for every year older than 25 . Finally, the return to official match play was expected after an average of 87.5 days, which is delayed of 44 days in the case of a grade III injury, 9 days in the case of a talar cartilage injury and of 1.1 day for every year younger than 25 , while shortened by 1.1 day for every year older than 25 .

\section{DISCUSSION}

The most important finding in our study is that the mean postoperative time required to begin sport-specific rehabilitation was $37 \pm 12$ days, the time to return to team training was $72 \pm 28$ days and the first official match was played on average after $103 \pm 28$ days, with $95 \%$ of injured football players returned to match-play within 6 months after surgery. In addition, we identified that injury severity (West Point III), concomitant talar cartilage injury and the age at time of surgery were associated with a longer rehabilitation times than West Point grade IIB injury, absence of cartilage injury and age $<25$ at time of surgery.

\section{Association between injury and return to play}

In our study, we differentiated the mean return to train time $(72$ days) and the mean return to play time (103 days) after unstable grade IIB and III syndesmotic ankle injuries in elite football. 


\begin{tabular}{|c|c|c|c|c|c|c|c|}
\hline \multicolumn{2}{|c|}{ Time landmarks } & \multicolumn{2}{|c|}{ Return to on field rehabilitation } & \multicolumn{2}{|c|}{ Return to train with team } & \multicolumn{2}{|c|}{ Return to first match } \\
\hline 0 months & 7 days (1 week) & - & - & - & - & - & - \\
\hline & 14 days (2 weeks) & $0 \%$ & (SE 0\%) & - & - & - & - \\
\hline & 21 days (3 weeks) & $4 \%$ & (SE 2\%) & $0 \%$ & (SE 0\%) & - & - \\
\hline & 28 days (4 weeks) & $19 \%$ & (SE 4\%) & $1 \%$ & (SE 1\%) & - & - \\
\hline \multirow[t]{4}{*}{1 month } & 35 days (5 weeks) & $55 \%$ & (SE 5\%) & $4 \%$ & (SE 2\%) & $0 \%$ & (SE $0 \%$ \\
\hline & 42 days ( 6 weeks) & $76 \%$ & (SE 4\%) & $10 \%$ & (SE 3\%) & $0 \%$ & (SE 0\%) \\
\hline & 49 days (7 weeks) & $86 \%$ & (SE 3\%) & $20 \%$ & (SE 4\%) & $1 \%$ & (SE 1\%) \\
\hline & 56 days (8 weeks) & $94 \%$ & (SE 2\%) & $35 \%$ & (SE 5\%) & $2 \%$ & (SE 1\%) \\
\hline \multirow[t]{4}{*}{2 months } & 63 days (9 weeks) & $97 \%$ & (SE 2\%) & $47 \%$ & (SE 5\%) & $4 \%$ & (SE $2 \%$ \\
\hline & 70 days (10 weeks) & $98 \%$ & (SE 1\%) & $56 \%$ & (SE 5\%) & $5 \%$ & (SE 2\%) \\
\hline & 77 days (11 weeks) & $99 \%$ & (SE 1\%) & $67 \%$ & (SE 4\%) & $16 \%$ & (SE 3\%) \\
\hline & 84 days (12 weeks) & $100 \%$ & (SE 0\%) & $69 \%$ & (SE 4\%) & $29 \%$ & (SE 4\%) \\
\hline \multirow[t]{4}{*}{3 months } & 91 days (13 weeks) & - & - & $73 \%$ & (SE 4\%) & $44 \%$ & (SE 5\% \\
\hline & 98 days (14 weeks) & - & - & $79 \%$ & (SE 4\%) & $53 \%$ & (SE 5\%) \\
\hline & 105 days ( 15 weeks) & - & - & $86 \%$ & (SE 3\%) & $60 \%$ & (SE 5\%) \\
\hline & 112 days ( 16 weeks) & - & - & $93 \%$ & (SE 2\%) & $66 \%$ & (SE 5\%) \\
\hline \multirow[t]{4}{*}{4 months } & 119 days (17 weeks) & - & - & $95 \%$ & (SE 2\%) & $76 \%$ & (SE $4 \%$ \\
\hline & 126 days (18 weeks) & - & - & $97 \%$ & (SE 2\%) & $85 \%$ & (SE 3\%) \\
\hline & 133 days (19 weeks) & - & - & $97 \%$ & (SE 2\%) & $91 \%$ & (SE 3\%) \\
\hline & 140 days (20 weeks) & - & - & $98 \%$ & (SE 1\%) & $93 \%$ & (SE 2\%) \\
\hline \multirow[t]{4}{*}{5 months } & 147 days (21 weeks) & - & - & $98 \%$ & (SE 1\%) & $95 \%$ & (SE $2 \%$ \\
\hline & 154 days (22 weeks) & - & - & $98 \%$ & (SE 1\%) & $97 \%$ & (SE 2\%) \\
\hline & 161 days (23 weeks) & - & - & $100 \%$ & (SE 0\%) & $97 \%$ & (SE 2\%) \\
\hline & 168 days (24 weeks) & - & - & & & $97 \%$ & (SE 2\%) \\
\hline \multirow[t]{4}{*}{6 months } & 175 days ( 25 weeks) & - & - & - & - & $98 \%$ & (SE 1\% \\
\hline & 182 days ( 26 weeks) & - & - & - & - & $98 \%$ & (SE 1\%) \\
\hline & 189 days (27 weeks) & - & - & - & - & $99 \%$ & (SE 1\%) \\
\hline & 196 days (28 weeks) & - & - & - & - & $100 \%$ & (SE 0\%) \\
\hline Mean \pm SD & & $37 \pm 12$ days & & $72 \pm 28$ days & & $103 \pm 28$ days & \\
\hline
\end{tabular}

A recent prospective study by Calder $e t$ al reported on 36 athletes with an unstable grade IIB ankle injury. In their surgically treated cohort, they observed a mean return to sport of 64 days. However, no comparison with grade III injuries was described but they did find an additional increase in return to sports of 21.5 days if a concomitant deltoid ligament lesion was apparent. In their study, no differentiation was made on whether return to sports meant sport-specific rehabilitation, team training or first official match. ${ }^{12}$

In our study on 110 elite football athletes, we compared grade IIB with grade III injuries (table 3 ) and observed a mean return to sport of 72 days (table 2). We also differentiated the time to return to sport-specific rehabilitation, team training and official match between grade IIB and grade III injuries. Beside from concomitant deltoid lesions (known as West Point grade III injury), we identified that concomitant cartilage injury and greater age were associated with significantly longer return to play times (table 1).

In division I collegiate American football players following high ankle sprains, there is a clear association between injury severity as measured by physical examination and the time to return to unrestricted play. Although these injuries are less common than isolated lateral ankle sprains, their clinical course was shown to be more protracted and unpredictable. ${ }^{13}$

A report on collegiate athletes with syndesmotic sprains also found an association between injury height on physical examination and time lost from athletic participation. ${ }^{14}$ Although this study was not restricted to football players only (without the effect of sex or sport in their results), similar mean times lost from athletic participation are reported (13.4 vs 15.5 days). ${ }^{14}$
Similar findings were observed in our study with a time to return to unrestricted play of 57 days (grade IIB) versus 105 days (grade III) which means an increase in time of 48 days based on injury severity (table 3).

When compared with time loss to play with lateral ankle sprains, numerous authors report a significantly greater time loss to play with high ankle sprains. ${ }^{12} 13$ 15-17 In professional football players this results in a higher inability to train (11.7 vs 3.5 training sessions) and play official matches (1.4 vs 0.3 matches) compared with those with simple lateral ankle sprains only. ${ }^{16}$ Furthermore, unstable syndesmotic injuries are associated with persistent ankle pain (40\%) and premature ankle arthritis (42\%) if left untreated. ${ }^{17}$

Indeed, although our study didn't look into the return to play after lateral ankle sprains, our findings confirm the longer rehabilitation time of high ankle sprains, compared with previous study results on lateral ankle sprains. ${ }^{9} 10$

\section{Strengths and limitations}

To our knowledge this study is the largest study looking at return to play after surgical stabilisation of syndesmosis injuries. In addition, it is the first study to report return to play data in a homogenous cohort of professional football players. Despite its strength, this study has some limitations.

The most important limitation is its retrospective design, as collection of return to play outcome data might have been influenced by recall bias. Furthermore, the treating physiotherapists and team medical staff had access to the imaging studies (MRI) and surgical notes, potentially biassing how they progressed 
Table 3 Return to sport according to injury severity

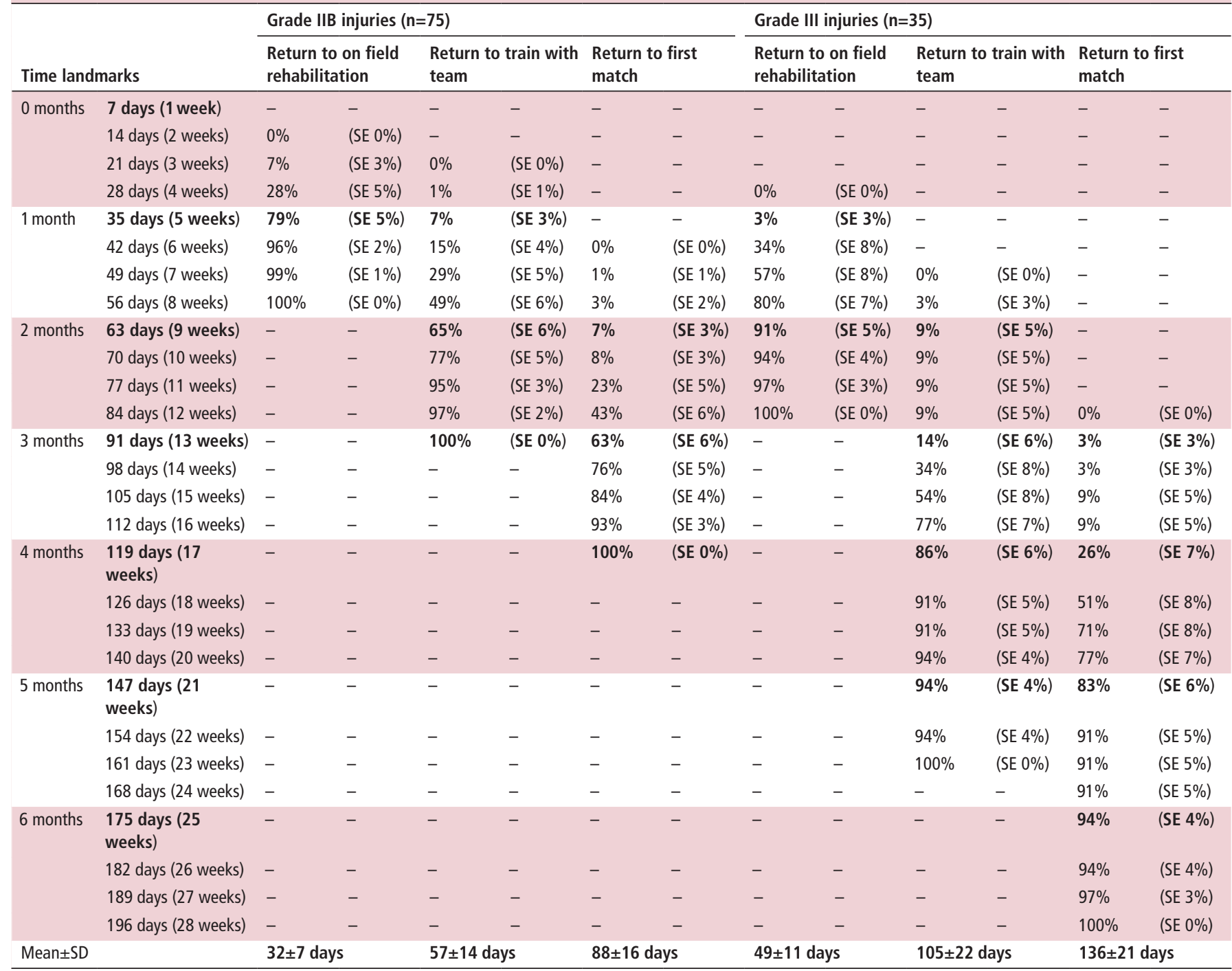

players through rehab and the return to play decision. The return to play information may have been confounded by heterogeneity of the ankle pathology as well, as patients with concomitant osteochondral defects were included in this study. In addition, as the follow-up was restricted to time to return to official match play, long-term functional outcome data is lacking.

\section{Clinical implications}

The findings of this study should allow physicians to better inform injured football players and their medical support staff on the mean return to play times that can be expected after surgical fixation of isolated unstable syndesmosis injuries. Additionally, the identification of three specific injury characteristics (West Point grade III injury, concomitant talar cartilage lesion and age $>25$ as being associated with longer time from surgery until match play), can assist in defining return to play expectations.
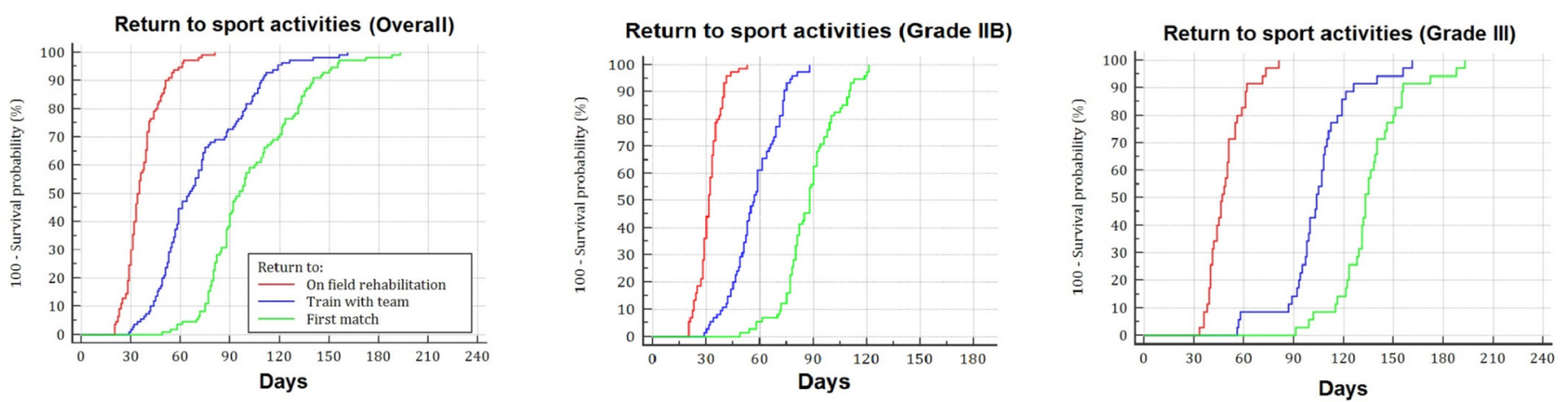

Figure 3 Graphic image on the time towards return to on field rehabilitation, training with team and first match. 

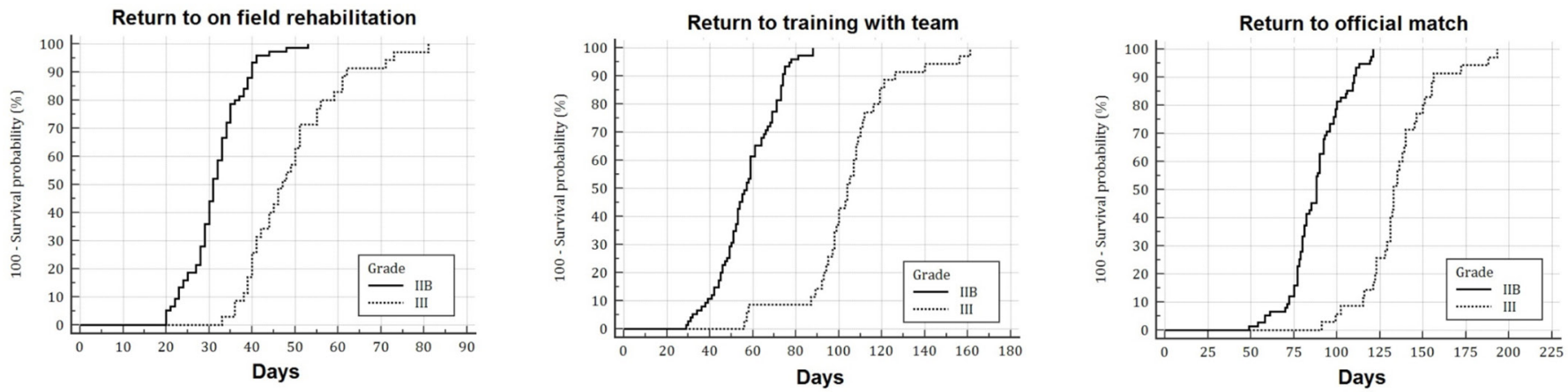

Figure 4 Graphic image on the specific characteristics of return to sports (overall, grade IIB, grade III).

\begin{tabular}{|c|c|c|c|c|c|c|c|c|c|}
\hline \multirow[b]{2}{*}{ Independent variables } & \multicolumn{3}{|c|}{ Return to on field rehabilitation } & \multicolumn{3}{|c|}{ Return to train with team } & \multicolumn{3}{|c|}{ Return to first match } \\
\hline & Coeff. & SE & $P$ value & Coeff. & SE & $P$ value & Coeff. & SE & $P$ value \\
\hline (Constant) & 31.2 & & & 56.4 & & & 87.5 & & \\
\hline Grade III injury & 15.7 & 1.8 & $<0.0001$ & 43.0 & 3.6 & $<0.0001$ & 43.8 & 3.8 & $<0.0001$ \\
\hline Cartilage injury & 4.4 & 2.0 & $=0.0277$ & 10.7 & 4.0 & $=0.0096$ & 9.2 & 4.2 & $=0.0311$ \\
\hline Age (years) & -0.4 & 0.2 & $=0.0460$ & -0.8 & 0.4 & $=0.0475$ & -1.1 & 0.4 & $=0.0121$ \\
\hline Injury during training & - & - & n.s. & - & - & n.s. & - & - & n.s. \\
\hline Reinjury & - & - & n.s. & - & - & n.s. & - & - & n.s. \\
\hline Contact injury & - & - & n.s. & - & - & n.s. & - & - & n.s. \\
\hline Dominant leg & - & - & n.s. & - & - & n.s. & - & - & n.s. \\
\hline Significance of the model & \multicolumn{3}{|c|}{$p<0.0001$} & \multicolumn{3}{|c|}{$p<0.0001$} & \multicolumn{3}{|c|}{$p<0.0001$} \\
\hline Residual SD & \multicolumn{3}{|l|}{8.0} & \multicolumn{3}{|l|}{16.3} & \multicolumn{3}{|l|}{16.9} \\
\hline
\end{tabular}

\section{CONCLUSION}

In our cohort of professional football players, surgical stabilisation of acute isolated unstable syndesmosis injury allowed for relatively quick return to field rehabilitation, team training and match play. We also identified that injury severity, concomitant talar cartilage injury and the age at time of surgery were associated with a significantly longer time to return to sport.

\section{What are the new findings?}

We established that the average time required to start with on field rehabilitation, team training and official match play in professional football players who were surgically treated for isolated unstable ankle joint distal syndesmosis injuries was, $37 \pm 12$ days, $72 \pm 28$ days and $103 \pm 28$ days, respectively. We also identified three specific injury characteristics (West Point grade III injury, concomitant talar cartilage lesion and age $>25$ ) as being associated with longer time from surgery until match play compared with West Point grade IIB injury, absence of cartilage injury and age $<25$.

\section{How might it impact on clinical practice in the future?}

- This study was performed to better inform injured football players and their medical support staff on the return to play times after surgical fixation of isolated unstable syndesmosis injuries.
Correction notice This article has been corrected since it published Online First. The affiliations have been corrected.

Acknowledgements The authors wish to express their gratitude to Miss Micheline Assaker from the Aspetar Hospital Research Department for her valued help in the study data collection.

Collaborators Micheline Assaker.

Contributors $\mathrm{PD}^{\prime} \mathrm{H}$ : design and acquisition of the work, interpretation of the data, writing. AG: analysis of the data. KA: acquisition of the work. JC: design of the work TB: acquisition of the work, writing review. SZ: interpretation of the data. JE: design of the work and writing review.

Funding The authors have not declared a specific grant for this research from any funding agency in the public, commercial or not-for-profit sectors.

Competing interests None declared.

Patient consent for publication Not required.

Ethics approval This study was conducted after receiving ethical approval by the Qatar Anti-Doping Lab review board (article reference: \#E2017000259).

Provenance and peer review Not commissioned; externally peer reviewed.

Data availability statement Data may be obtained from a third party and are not publicly available.

Author note Investigation performed at Aspetar Orthopaedic and Sports Medicine Hospital, Doha, Qatar

Open access This is an open access article distributed in accordance with the Creative Commons Attribution Non Commercial (CC BY-NC 4.0) license, which permits others to distribute, remix, adapt, build upon this work non-commercially, and license their derivative works on different terms, provided the original work is properly cited, appropriate credit is given, any changes made indicated, and the use is non-commercial. See: http://creativecommons.org/licenses/by-nc/4.0/.

\section{ORCID iDs}

Pieter D'Hooghe http://orcid.org/0000-0003-0003-6305

Alberto Grassi http://orcid.org/0000-0003-4236-1798 


\section{REFERENCES}

1. Lubberts $B, D^{\prime}$ Hooghe $P$, Bengtsson $H$, et al. Epidemiology and return to play following isolated syndesmotic injuries in professional football players. Br I Sports Med 2017;21.

2. Waldén $M$, Hägglund $M$, Ekstrand J. Time-trends and circumstances surrounding ankle injuries in men's professional football: an 11-year follow-up of the UEFA champions League injury study. Br J Sports Med 2013;47:748-53.

3. Sman AD, Hiller CE, Refshauge KM. Diagnostic accuracy of clinical tests for diagnosis of ankle syndesmosis injury: a systematic review. Br I Sports Med 2013;47:620-8.

4. Sman AD, Hiller $C E$, Rae $K$, et al. Diagnostic accuracy of clinical tests for ankle syndesmosis injury. Br J Sports Med 2015;49:323-9.

5. D'Hooghe P, York PJ, Kaux JF, et al. Fixation techniques in lower extremity Syndesmotic injuries. Foot Ankle Int 2017;38:1278-88.

6. Hunt KJ, Injuries S. Syndesmosis injuries. Curr Rev Musculoskelet Med 2013;6:304-12.

7. D'Hooghe P, Bouhdida S, Whiteley R, et al. Stable versus unstable grade 2 high ankle Sprains in athletes: a noninvasive tool to predict the need for surgical fixation. Clin Res Foot Ankle 2018;6:252-8.

8. Hunt KJ, Phisitkul P, Pirolo J, et al. High ankle Sprains and Syndesmotic injuries in athletes. J Am Acad Orthop Surg 2015;23:661-73.

9. Roemer FW, Jomaah N, Niu J, et al. Ligamentous injuries and the risk of associated tissue damage in acute ankle Sprains in athletes. Am J Sports Med 2014;42:1549-57.
10. Osbahr DC, Drakos MC, O'Loughlin PF, et al. Syndesmosis and lateral ankle Sprains in the National football League. Orthopedics 2013;36:e1378-84.

11. McCollum GA, van den Bekerom MPJ, Kerkhoffs GMMJ, et al. Syndesmosis and deltoid ligament injuries in the athlete. Knee Surg Sports Traumatol Arthrosc 2013;21:1328-37.

12. Calder JD, Bamford R, Petrie A, et al. Stable versus unstable grade II high ankle Sprains: a prospective study predicting the need for surgical stabilization and time to return to sports. Arthroscopy 2016;32:634-42.

13. Miller BS, Downie BK, Johnson PD, et al. Time to return to play after high ankle Sprains in collegiate football players. Sports Health 2012;4:504-9.

14. Nussbaum ED, Hosea TM, Sieler SD, et al. Prospective evaluation of syndesmotic ankle sprains without diastasis. Am J Sports Med 2001;29:31-5.

15. Förschner PF, Beitzel $K$, Imhoff $A B$, et al. Five-Year outcomes after treatment for acute instability of the tibiofibular Syndesmosis using a Suture-Button fixation system. Orth J Sports Med 2017;5:232596711770285-7.

16. Takao M, Ochi M, Oae K, et al. Diagnosis of a tear of the distal tibiofibular syndesmosis: the role of arthroscopy of the ankle. J Bone Joint Surg Br 2003;85:324-9.

17. van Dijk CN, Longo UG, Loppini M, et al. Conservative and surgical management of acute isolated syndesmotic injuries: ESSKA-AFAS consensus and guidelines. Knee Surg Sports Traumatol Arthrosc 2016;24:1217-27. 